vol.7 No.1 - 2020

\title{
MOTHERS' KNOWLEDGE AND SUBJECTIVE PRACTICE TOWARD MOST COMMON DOMESTIC INJURIES AMONG UNDER-FIVE CHILDREN
}

\author{
Heba M. Nageh ${ }^{1}$, Samar EL. Abd El-Raouf ${ }^{2}$, Samia M. Abd El-Mouty ${ }^{3}$ \\ ${ }^{I}$ Demonstrator, Community Health Nursing department, Faculty of Nursing, \\ Mansoura University, Egypt \\ ${ }^{2}$ Assist. Professor, Community Health Nursing department, Faculty of Nursing, \\ Mansoura University, Egypt \\ ${ }^{3}$ Assist. Professor, Community Health Nursing department, Faculty of Nursing, \\ Mansoura University, Egypt
}

\begin{abstract}
Background: Domestic injuries are one of the greatest public health challenges in the 21st century especially in low and middle income countries (LMICs) with considerable association between social and economic costs. These injuries are common among children under-five in rural Egypt. Poisoning, burns, falls, wounds are common causes of children injuries at their homes. There are so many factors that had a direct or indirect effect on children injuries including child age, gender and behavior, maternal education, family socio-economic status and number and home environment. Therefore, it's important to increase mothers` knowledge and practice continuously to be cared of their children. This study aimed to assess mothers' knowledge and subjective practice toward most common domestic injuries among under-five children. A cross sectional study design was utilized to accomplish this study at Mansoura locality from both urban and rural areas (Mansoura city and El-Baramoun village) through home visits. Convenience sampling technique was used in this study and 100 mothers of under-five children from both genders were included in the sample, while excluding children with special needs. The study was conducted throughout preparation phase, operational phase including literature review and developing the study tools and implementation phase including initial data collection. Results. Study results revealed that more than of the studied mothers had secondary education. Less than half of the studied children' age ranged from 2 to less than 3 years during occurrence of domestic injury, moreover about one fourth of them their injuries were caused by falls, in addition to about three fourths occurred due to unsafe home environment. Consequently less than two thirds of studied children exposed to low risk which can be treated at home. All of the studied mothers had improper practice regarding to burns, falls, poisoning. Conclusion. The home environment is a common place for injuries among under-five children in rural and urban areas in Mansoura locality. Additionally, mothers' subjective practices regarding to most common domestic injuries are improper and as well knowledge of them on such injuries are poor. Finally, it is recommended that continuous health education program and training courses regarding domestic safety for children and first aid measures for the mothers who have under-five children.
\end{abstract}

Keywords: Domestic injury., Knowledge, Practice, Under five child

\section{Introduction}

Injury was defined as "the physical damage which results when a human body is suddenly subjected to excessive amount of energy, which exceeds the threshold of the physiological tolerance" (1). Domestic injuries are one of the greatest public health challenges in the 21 st century especially in low and middle 
Heba M. Nageh et. al.

income countries (LMICs) with considerable association between social and economic costs (2).

Additionally, the World Health Organization (WHO) estimates that there are millions of injuries are in emergent need for hospital treatment, but hospital admission and Emergency Department (ED) injury data is unavailable globally specifically for the most of LMICs (3). These injuries are common among children younger than five years of age in rural Egypt such as burns and falls (4), whereas globally are the leading cause of morbidity and mortality (5). Besides it have an increased impact on individuals, families and communities causing disabilities and premature death (3).

Considering the picture of a completely unbalanced state between the child and its environment, there are 223 million young citizens who died over the past two decades before the age of five years (6). Therefore, the call for public health attention to these injuries has been launched around the world and a great emphasis has been considered to LMICs (7).

There are so many factors that had a direct or indirect effect on children injuries. These include child age, gender and behavior, maternal education, family socio-economic status, structure and number and home environment (8). In low and middle income countries, there isn't any stated policy against the protection of children from household hazard injuries. The childhood home injuries are multifactorial and usually occur because of poor safety measures of children and their unusual curiosity. Moreover, fatigue and carelessness of caregiver and maternal depression are also associated to the causes of childhood home injuries (9).
National Institute for Health and Clinical Excellence (10) mentioned that home refers to the house, garden and the property boundaries. Findings prove that the home is the primary place for child injuries especially in under two children (11). Studies done in many Mediterranean East countries have shown that children injuries are most common at home (12). Because of the long period of time that the child spends at home, a substantial proportion of childhood injuries take place in this setting $(13,14,15)$. Many of the home devices may cause injuries to children in forms of poisoning, burns, electric shock, drowning, falls, etc. (16).

A study carried in Pakistan (17) indicated that falls, poisoning, burns, wounds and swallowing of foreign objects are common cause of children injuries at their homes. In addition to a community based study conducted in urban Delhi (18) stated that most of injuries occurred at home especially accidental falls.

In United States, home injuries cause death of a person in every three minutes and according to the report of Healthcare Research and Quality (HCRQ), injuries cause about $17 \%$ of total medical visits to $\mathrm{ED}$, whereas one quarter of cases are children and adolescents (19). In Iraq, one of the primary causes of death between the under five children was home accidents (20), but in Africa, home injuries are graded among the top ten morbidity and mortality causes in all age groups (21).

There are different proven methods that could minimize the occurrence and the severity of childhood home injuries and nearly $90 \%$ of cases could be prevented by public education and environmental modification (22). Therefore, it is important to improve mothers` knowledge and practice continuously to be cared of their children.

Consequently, community health nurse involvement in certain areas as homes 
is necessary to identify household risks, reduce environmental hazards, achieve public policies and apply community programs through a broad range of interventions as parental education (23).

\section{Aims of the Study}

1. To assess mothers' knowledge toward most common domestic injuries among under five children.

2. To assess mothers' subjective practice toward most common domestic injuries among under five children.

\section{Method}

Design

A cross sectional study design was utilized to accomplish this study.

\section{Setting}

The study was carried out through home visits at Mansoura locality from both urban and rural areas (Mansoura city and El-Baramoun village).

\section{Participants}

A convenient sample technique was used in this study as consecutively selected through home visits according to the convenient accessibility of 100 mothers of under-five children from both genders, while excluding children with special needs. The sampling process comes to an end the time plan limit are reached.

\section{Tools for Data Collection}

Five tools were used in this study (I, II, III and IV" included two parts; part I \& part II") developed by the researcher for data collection as the following:

Tool I: Structured interview to assess mothers' and their under-five children's socio-demographic and economic characteristics: this tool was used to assess socio-demographic and economic characteristics of mothers and their under-five children including; age, education, occupation, marital status, family income, residence, family structure, family size and number of under-five children, as well child age, child gender, child rank.

Tool II: Observation checklist to assess home environment: this tool was used to assess home environment, which include eight categories: rooms and home components, kitchens, bathrooms, electrical appliances, stairs and toxic substances. For each categorized item; answer choices included "Yes", "No" or "Not have".

Tool III: Structured interview to assess mothers' knowledge toward most common domestic injuries: this tool was used to assess mothers' knowledge about most common domestic injuries as; meaning of home injuries, causes, risky groups, most common types, consequences and prevention of this injuries. The tool was classified into nine category; all of these categories were composed of 17 question. One mark awarded for each correct answer. The total score of knowledge ranged from 0 to 110 . According to the researcher's cut of point, the knowledge level was categorized into three categories as:

- Poor $=$ scores less than $50 \%$ of total scores (less than 55)

- Fair $=$ scores $50 \%$ to less than $75 \%$ of total sores (55 to less than 82.5)

- Good = scores more than $75 \%$ of total scores (82.5 and more)

Tool IV: Structured interview to assess mothers' subjective practice toward most common domestic injuries: it consists of two parts as the following:

Part I: Structured interview to assess mothers' experience related to: previous history of domestic injuries; this tool was based on one question about if the under-five child was previously exposed to domestic injury? If the answer was "Yes"; there are six questions should be answered 
about: child age during the injury, type, cause and severity of this injury.

Part II: Structured interview to assess mothers' subjective practice related to: Safety measures taken at home environment to prevent most common domestic injuries. The tool was classified into three categories which are composed of 29 questions. One mark awarded for each correct answer. The total score of subjective practice ranged from 0 to 29 . According to the researcher's cut of point, the subjective practice was consisted of two categories as:

- Improper $=$ scores less than $75 \%$ of total scores (less than 21.75)

- Proper $=$ scores more than $75 \%$ of total scores (21.75 and more)

\section{Procedure}

\section{Preparation phase:}

\section{Administrative stage}

- An official letter was issued from the Faculty of Nursing, Mansoura University to the appropriate authorities in the selected settings to permit the researcher to carry out the study.

\section{Ethical consideration}

- An approval was obtained from Research Ethics Committee of Faculty of Nursing, Mansoura University.

- An approval was obtained from the participants. The researcher introduced herself and a simple explanation about the aims of the study given to them. They assured that their participation in the study was voluntary and the collected data treated confidentially and only used for the purpose of the study. Participants were informed that they have the right to withdraw at any time from the study without giving any reason.

\section{Operational phase}

1-Literature review

- Review of national and international literatures on the various aspects of fall, burn and poisoning injuries at home was proposed from scientific published articles, internet search and textbooks. This review was a guide for developing the study tools.

2-Developing of the study tools: the tools (I to IV) were developed by the researcher after reviewing the related literature.

The validity of the study was tested by:

a) Juries that involved five experts in the field of community health nursing tested the validity of the developed tools and the required modifications were carried out.

b) A pilot study on $10 \%$ of the study sample (10 mothers of under-five children) was selected conveniently from the main study settings but not included in the study sample. The pilot study carried out to test the validity and applicability of the study tools for estimation of the approximate time required for data collection, identifying the possible obstacles that may hinder data collection. Accordingly, the required modifications were done, so some questions were added and others were omitted.

c) The developed tools were tested for their reliability by using Cronbach's Alpha test in (Statistical Product and Service Solutions) SPSS program version 20, which was carried out on the pilot study and the results were as the following:

- The Cronbach's Alpha was 0.99 for the mothers' knowledge tool. 
- The Cronbach's Alpha was 0.96 for the mothers' subjective practice tool.

\section{Implementation phase}

\section{- Initial data collection:}

a) The duration of data collection was approximately 12 weeks from October 2017 to December 2017.

b) Each mother of under-five children was interviewed individually. The researcher introduced herself and explained the purpose and the method of the study. Each interview consumed about (25 - 30 minutes) to complete filling of the study tool that depended on understanding and responding of the mothers.

c) The researcher used data collection tools to assess mothers and their children socio-demographic and economic characteristics, mothers' knowledge and subjective practice toward most common domestic injuries (Tools I, III and IV), also the researcher used observation checklist to assess home environment (Tool II).

\section{- Statistical analysis}

- Data were sorted, coded, organized, categorized and then transferred into especially designed formats.

- Data were analyzed using SPSS (Statistical Product and Service Solutions) version 20.

- Data were presented by using descriptive statistics in the form of frequencies and percentage.

- Mean (M) and standard deviation (SD) were calculated for continuous variables.

\section{Results}

Table (1) shows that the age of the studied mothers ranged from less than 20 to less than 50 with a mean age of 24.7 (5.7) and 61 of them categorized from 20 to less than 30 years. As regards to educational level, 52 of the studied mothers had secondary education, 57 of them were housewives and 72 had hardly an adequate income per month.

Table (2) indicates that 64 of the studied mothers lived in extended family and 72 and 60 of them had four members and more in their families and only one child under five respectively.

Figure (1) shows that 18 of the studied children were cared by their grandmothers in absence of their mothers, while 15 of them were cared by one of their brotherhood.

Table (3) presents that $31.0 \%$ of the studied children' age ranged from 2 to less than 3 years, $43.2 \%$ of them were in the second rank of their siblings and $41.7 \%$ of them went to nursery.

Table (4) reveals that $46.0 \%$ of the studied children' age ranged from 2 to less than 3 years during occurrence of injury, moreover $41.3 \%$ of them their injuries were caused by wounds, in addition to $74.6 \%, 71.4 \%, 68.3 \%$ and $55.6 \%$ of the studied children were injured due to unsafe home environment, playing or naughtiness, lack of the mothers' care and lastly child's inability to distinguish dangerous substances respectively. Consequently $60.3 \%$ of them exposed to low risk which can be treated at home.

Table (5) concerns mothers' homes components, 58, 54 and 57 of the studied mothers homes had chairs or tables near to windows or balconies, windows without grates and child' beds without barriers respectively. Additionally 69 of the studied mothers' homes had insufficient lighting at night. Regarding to homes kitchens 
and bathrooms 60 and 52 of them leaved the kitchen and bathroom floors wet respectively. Besides 64, 39 and 42 of the studied mothers leaved matches or lighters on tables, leaved cooking pots' panhandle out-bounded in front of the stove and their kitchen drawers easily opened respectively, in addition to that 96 of them didn't have smoking alarm in their kitchen or homes. As regards to homes stairs, 44 and 44 of the studied mothers' homes didn't have handrails for stairs and had wide stairs which not suitable for children respectively; however 91 of them their homes didn't have gates or safety barriers on front of stairs. According to toxic substances in the homes, 75 and 73 of the studied mothers stored detergents and medicines in accessible places for children respectively, in addition to 71 of them put liquid detergents in the drinking water bottles or in bottles of carbonated water.

Table (6) indicates that 54, 68, 70, 65, 100 and 100 of the studied mothers had poor knowledge about meaning, risky groups, causes, types, common consequences and ways of prevention about domestic injuries with a mean .460 (.501), 2.180 (1.038), 3.210 (1.659), 4.550 (2.213), .950 (.219) and 2.380 (1.003) respectively. Concerning to poisoning, 83, 88, 90 and 90 of the studied mothers had poor knowledge about types, causes, symptoms and prevention of poisoning with a mean $.870(.676)$, 2.260 (1.169), 3.280 (2.156) and $2.970 \quad$ (1.566) respectively. Regarding to burns, 78, 100, 98,
100 and 100 of the studied mothers had poor knowledge about burns types, causes, prevention during bathing, prevention from hot liquids or foods and from hot materials or appliances with a mean 1.140 (.532), 1.740 (.525), .940 (.312), 2.480 (.926) and $1.660 \quad(.655)$ respectively. According to falls, 96 and 95 of the studied mothers had poor knowledge about causes and prevention of falls with a mean 2.530 (1.058) and 3.180 (1.559) respectively.

Figure (2) shows that 55, 59, 56 and 53 of the studied mothers acquired their knowledge from media, parents, relatives or friends and self-experience respectively.

Table (7) represents that 100 of the studied mothers had improper practice regarding to poisoning, burns and falls with a mean 3.390 (1.286), 2.010 $\begin{array}{lll}(.688) & \text { and } & 5.480 \quad(1.141) \text { and }\end{array}$ respectively.

\section{Discussion}

Young children are vulnerable to injuries due to their innate desire to explore the world, seek answers to thoughts and unawareness of the dangers. Hence putting themselves at risk, so minor injuries are inevitable but providing a safe home environment and close supervision $(\mathbf{2 4}, \mathbf{2 5})$.

The current study revealed that less than two thirds of studied mothers aged from 20 to less than 30 years, with a mean of 24.740 (5.788) years. This finding is at the same line with a study who conducted about "Home Unintentional Non-fatal Injury among Children Under-five Years of Age in a Rural Area, El Minia Governorate, Egypt" (4) which found that about two thirds of mothers aged from 21 to 30 years old. While two studies carried in Saudi Arabia $(\mathbf{2 6 , 2 7 )}$ indicated that the mothers aged from 20 to 43 years, with a mean of $29.56(5.42)$ years. 
As regards, studied mothers' educational level, the current study showed that more than half had a secondary education and a few of them had a postgraduate degree. From the researcher point of view, the families in Mansoura locality prefer the secondary education for their girls for earlier marriage. These findings are in a disagreement with two studies, the first one affiliated to Egypt, but the second to Saudi Arabia $(\mathbf{2 5}, \mathbf{2 7})$ which indicated that less than half of the participants had a secondary education. Furthermore, others studies carried in rural Egypt and Turkey revealed that more than half and more than two thirds of mothers were primary school graduates and illiterate respectively $(4,28)$.

Regarding the mothers working status, in the current study more than half of them were housewives as the used sampling technique was convenient and applied during home visits in rural and urban areas at Mansoura locality. This finding is in agreement with three studies conducted in Middle Eastern countries in Egypt and Saudi Arabia (25, 27, 29) which indicated that the majority of mothers were not working. However, a study in Cairo and Benha University Hospital found that more than half of mothers were working (30).

Concerning family structure; the current study showed that less than two thirds of the studied mothers lived in extended families and this finding is in consistent with Egyptian and Turkish studies' findings $(\mathbf{2 8}, \mathbf{3 1})$ that indicated most of the participants belonged to extended families.

As regards family size, less than three fourths of families were four members and ever more, with a mean 4.030 (.904). This finding is in the same line with a study affiliated in rural area in
Iran (32) which mentioned that average family size was 3.97 . While an Egyptian study (29) determined that more than one third of the family size was four members.

In the current study, the grandmothers were responsible for caring of less than half of the children of working mothers whereas the working mothers were less than half of the studied mothers. This finding is in a disagreement with a study applied at Iran (32) whose conducted about" Home-Related Injuries among Under-FiveYear Children and Mothers' Care regarding Injury Prevention in Rural Areas of Twiserkan" and concluded that most of children are cared by their grandmothers in absence of mothers.

Concerning the nursery attendance; in the current study less than half of the studied mothers' children went to nursery as both employed and unemployed mothers sent their children to the nursery. This finding is in contrast with a retrospective cohort study implemented in Egypt (25) which found that a few attended nursery but the majority of children didn't.

Concerning the children previous history to home injuries, in the current study less than half of the studied children exposed to home injuries earlier than the study. This finding is in the same line with two descriptive studies applied in Iran and Turkey $(\mathbf{3 2}, \mathbf{3 3})$. However Egyptian studies $(4,29)$ represented that less than one fourth of 234 rural Egyptian under-five children in Sharkia and 1255 in El-Minia had home injuries in the previous-years respectively had home injuries in the previous years.

Regarding the previous most frequent types of home injuries, the current study indicated that wounds represented less than half followed by falls were about one fourth and then burns were less than one fourth, all occurred due to leave of fragile objects such as bottles or mugs in the reach of children, absence of handrails 
on the stairs and leave hot cooking utensils accessible to children. A similar trend is obtained by all researchers in the following different studies implemented in Saudi Arabia, Egypt and Ghana $(27,29,30)$ which found that cut wounds represented the highest percentage of home injuries among the studied children. While others studies aimed to assess home-related injuries among under-five children $(\mathbf{4}, \mathbf{2 8}, \mathbf{3 1}$, $34,35)$ clarified that the most frequent home injuries were falls and burns.

Concerning the causes of previous home injuries, the current study indicated that about three fourths of home injuries resulted from unsafe home environment as placing chairs or tables near to windows or balconies, leaving the floors wet, storing detergents and medicines in accessible places for children, etc. This finding is in agreement with a study aimed to assess mothers' care regarding home injury prevention in rural areas in Iran (32) whose undertook to assess factors associated with home-related injuries among under-five children and revealed that most of home burns injuries occurred due to exposure to boiling liquids such as milk, tea, boiling water, soup,... moreover, falling from stairs, ladders, balcony and toys on the ground were important causes of children home injuries.

As regards to the severity of previous injuries, the current study represented that less than two thirds of injuries were mild with low risk and treated at home. This finding is quite similar to an Iranian study (32) which showed that the severity of injuries' children sustained were mild, moderate and severe injuries respectively, as these data were gathered using questionnaire and through interview with injured under-five children's mothers also identified from recorded information in Twiserkan Health Center in Twiserkan country, Iran.

The home is a perfect place to care for children. However, many caregivers fail to realize that it is the most common place where home injuries happen in developing countries. This may be related to that children spend most of time at their homes especially in the younger ages, so they will be exposed to various numbers of risks if mothers don't take the needed precautions $(36,37)$.

As regards to walkers in the homes, in the current study more than half of the studied families had walkers, while this finding is in contrast with a study conducted to investigate parents' attitudes to preventive measures of unintentional childhood injury and the parental adherence to these measures in Ankara, Turkey (38) and reported that the prevalence of walkers' usage was more than one fourth.

Concerning the homes kitchens, in the current study less than two thirds of the studied mothers left matches on tables accessible to children and more than one third of them left cooking utensils in the reach of children. These findings disagree with Saudi study (26) which found that only $11.4 \%$ of caregivers kept cigarettes and lighters accessible to children and approximately $12.6 \%$ kept the pots and the pans in reach for children.

Moreover, in the current study, most of the studied mothers didn't have smoking alarm in their homes and only $4.0 \%$ had it. This finding is in the same line with Saudi study (27) which reported that only $17.0 \%$ of homes had smoke alarms. However, an American study (39) is in contrast with the findings, reported that the majority of homes have smoke alarms.

As regards to the toxic substances in the homes, the current study indicated that less than three fourths of the studied 
mothers put liquid detergents in the drinking water bottles and also stored medicines in accessible places for children furthermore three fourths of mothers stored detergents in the reach of children. These findings are in disagreement with European study about" Parents' Perceptions, Attitudes and Behaviors towards Child Safety: A study in 14 European Countries" (40) which reported that more than three fourths of mothers kept the liquid detergents in their original packages and less than one fourth stored medicines and detergents in the reach of children, also these findings disagree with Egyptian study about" Determinants of Acute Poisoning among Children (1-60) months Old at a Poisoning Unit of a University Hospital, Egypt, are Employed Mothers a Risk Factor?" (25) which observed that less than half of mothers kept the detergents in nonoriginal bottles in the reach of children.

It's difficult to protect the children from home injuries by parents because of the inability to maintain their children under close supervision constantly and lack of awareness about causes and risk factors of accidents (41). Furthermore caregivers especially mothers play a critical role in providing a safe home environment for their children to minimize or prevent the home injuries (29).

Regarding studied mothers' score level of knowledge about causes of domestic injuries, the current study mentioned that less than three fourths of the studied mothers had poor knowledge. This finding is in line with a study applied in Saudi Arabia (27) which conducted about" Knowledge, Attitude and Practices of Mothers towards Home Accidents among Children, Makkah, $\mathrm{KSA}^{\prime}$ and revealed that more than half of mothers had unsatisfactory level of knowledge about causes of home accidents. Besides Egyptian study about" Mother's Education and Her Knowledge about Home Accident Prevention among Preschool Children in Rural Area in Sharkia Governorate" (42) and reported that more than half of the mothers didn't know anything about causes of home accidents which their children might be exposed.

According to studied mothers' score level of knowledge about types of domestic injuries, the current study revealed that about two thirds of the studied mothers had poor knowledge as more than half of them had a secondary education. This finding is similar to a study aimed to assess home injuries and related factors among children under-five in Turkey (28) which mentioned that more than half of the study sample had poor knowledge about types of home injuries.

Concerning studied mothers' score level of knowledge about prevention of domestic injuries, the current study showed that all the studied mothers had poor knowledge as more than three fourths of them didn't attend any health education programs about home injuries before. This finding is quite similar with three different studies aimed to assess mothers' knowledge of home accident prevention and carried in different areas; the first conducted in Saudi Arabia, (27) revealed that high percentage of mothers had unsatisfactory level of knowledge about the preventive measures of home injuries; furthermore the second carried in Baghdad, (43) found that mothers' knowledge was deficient in prevention of home accidents. In addition to, the third implemented in china, (44) concluded that parental knowledge about home injury prevention and safety promotion was unsatisfactory. However, these findings are in a disagreement with an Iranian study (45) which represented that three fourths of 
mothers had good knowledge about preventive measures of home injuries.

Regarding studied mothers subjective practice related to safety measures taken at home environment to prevent domestic injuries, in the current study all the studied mothers had improper experience in case of poisoning, burns and falls as more than half and one fourth of the studied mothers had secondary educational degree and adequate and reserve income per month. These findings are similar to a study aimed to assess home-safety measures adopted by mothers in India (46) which indicated that the majority of mothers had low level of safety measures' practice. However, another study that aimed to assess parent's adherence to children's home accident preventive measures, (47) found that more than two thirds of the parental adherence to the preventive measures of children home injuries wasn't satisfactory.

\section{Conclusion}

The study concluded that the home environment is a common place for injuries among under-five children in rural and urban areas in Mansoura locality. Therefore, measures should be taken to prevent children from the most common domestic injuries such as falls, burns and poisoning. Similarly, this study found that mothers' subjective practices regarding to most common domestic injuries are improper. In addition to, mothers' knowledge on such injuries are poor.

\section{Recommendations}

Based on the findings of the study, the following recommendations are suggested:

1. Continuous health education program and training courses regarding domestic safety for children and first aid measures for the mothers who have under-five children.

2. The mass media should be involved regarding to increase public awareness about home injuries through view videos for the way to designed and arranged the homes for preventing home injuries.

3. Counseling for mothers about usage of safety measures in home to overcome and avoid home injuries among underfive children.

4. Several studies are required to determine the impact of a health education intervention on minimizing the rate of exposure to home injuries.

\section{Acknowledgements}

We would like to thank all the mothers who participated in the study and appreciate the great efforts of the supervisors in this work. 
MOTHERS' KNOWLEDGE AND SUBJECTIVE etc...

Table 1:Mothers' socio-demographic and economic characteristics

\begin{tabular}{lc}
\hline \multicolumn{1}{c}{ Items } & $\mathbf{n = 1 0 0}$ \\
\hline Age: & 20 \\
\hline Less than 20 years & 61 \\
From 20 to less than 30 years & 17 \\
From 30 to less than 40 years & 2 \\
From 40 to less than 50 years & $24.740(5.788)$ \\
\hline Mean (SD) & 50 \\
\hline Residence: & 50 \\
\hline Rural & \\
Urban & 52 \\
Education: & 14 \\
\hline Secondary education & 30 \\
Intermediate education & 4 \\
University graduate & \\
Postgraduate degree & 57 \\
Occupation: & 38 \\
\hline Housewife & 5 \\
Clerk & \\
Worker & 99 \\
Marital status: & 1 \\
\hline Married & \\
Divorced & 25 \\
\hline Income/Month: & 32 \\
Adequate & \\
\hline Inadequate, Borrow & \\
\hline
\end{tabular}

Table 2:Mothers' family patterns

\begin{tabular}{lc}
\hline \multicolumn{1}{c}{ Items } & $\mathbf{n = 1 0 0}$ \\
\hline Family structure: & \\
\hline Extended & 64 \\
Nuclear & 36 \\
Number of family members: & \\
\hline less than 4 members & 28 \\
4 members and more & 72 \\
\hline Mean (SD) & $4.030(.904)$ \\
\hline Number of children under five: & 60 \\
\hline One child & 40 \\
\hline Two children & $1.400(.492)$ \\
\hline Mean (SD) & \\
\hline
\end{tabular}




\section{Heba M. Nageh et. al.}

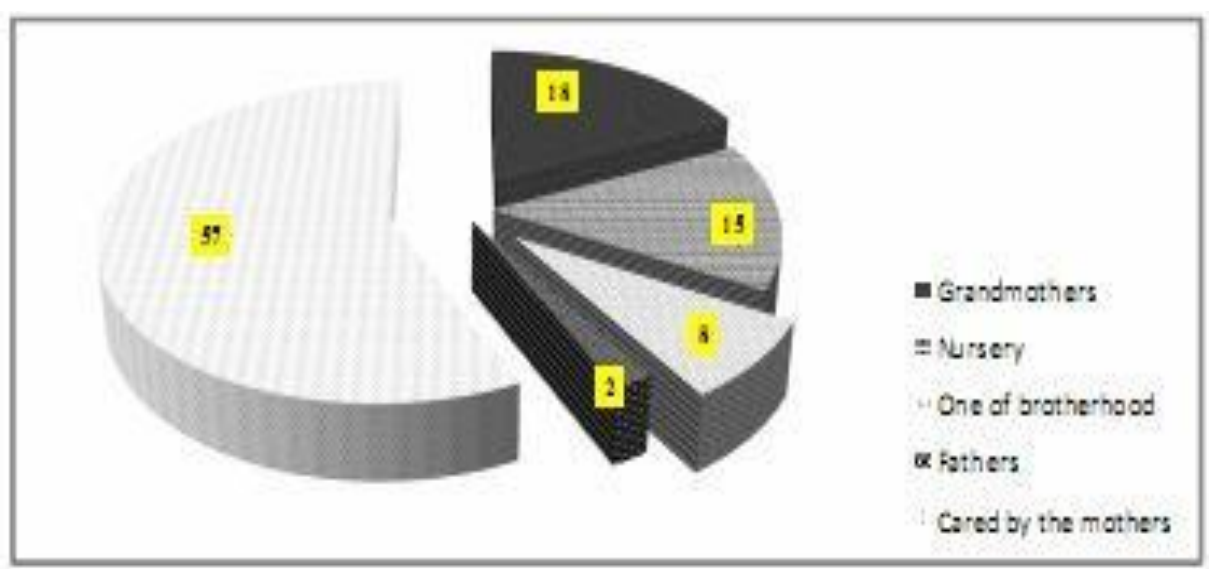

Figure 1

Person who caring for the child in absence of mother*

* The total number of employed mothers is 43 (worker and clerk)

Table 3:Under-five children' demographic characteristics

\begin{tabular}{lcc}
\hline \multicolumn{1}{c}{ Items } & $\mathbf{n = 1 3 9}$ & \% \\
\hline Age: & & \\
\hline less than 1 year & 22 & 15.8 \\
From 1 to less than 2 years & 28 & 20.1 \\
From 2 to less than 3 years & 43 & 31.0 \\
From 3 to less than 4 years & 33 & 23.7 \\
From 4 to less than 5 years & 13 & 9.4 \\
Gender: & & \\
\hline Girl & 70 & 50.4 \\
Boy & 69 & 49.6 \\
Child ranking: & & \\
\hline First child & 53 & 38.1 \\
Second child & 60 & 43.2 \\
Third child & 24 & 17.3 \\
Fourth child & 2 & 1.4 \\
Going to nursery & 58 & 41.7 \\
\hline
\end{tabular}


MOTHERS' KNOWLEDGE AND SUBJECTIVE etc...

Table 4:Under-five children' previous history of domestic injuries

\begin{tabular}{|c|c|c|}
\hline Items & $n=63$ & $\%$ \\
\hline \multicolumn{3}{|l|}{ Child's age during occurrence of injury*: } \\
\hline less than 1 year & 7 & 11.1 \\
\hline From 1 to less than 2 year & 28 & 44.4 \\
\hline From 2 to less than 3 year & 29 & 46.0 \\
\hline From 3 to less than 4 year & 7 & 11.1 \\
\hline From 4 to less than 5 year & 5 & 8.0 \\
\hline \multicolumn{3}{|l|}{ Types of injury: } \\
\hline Wounds & 26 & 41.3 \\
\hline Falls & 16 & 25.4 \\
\hline Burns & 12 & 19.0 \\
\hline Poisoning & 5 & 8.0 \\
\hline Electrical shocks & 4 & 6.3 \\
\hline \multicolumn{3}{|l|}{ Causes of injury $* *$ : } \\
\hline Unsafe home environment & 47 & 74.6 \\
\hline Playing / Naughtiness & 45 & 71.4 \\
\hline Lack of the mothers' care & 43 & 68.3 \\
\hline $\begin{array}{l}\text { The child's inability to distinguish } \\
\text { dangerous substances }\end{array}$ & 35 & 55.6 \\
\hline Child's presence alone at home & 24 & 38.1 \\
\hline Availability of hazardous substances & 12 & 19.0 \\
\hline $\begin{array}{l}\text { The presence of a child with one of his /her siblings } \\
<10 \text { years }\end{array}$ & 7 & 11.1 \\
\hline \multicolumn{3}{|l|}{ Degree of severity: } \\
\hline Low risk, treated at home & 38 & 60.3 \\
\hline Moderate risk, consulted with the nearest pharmacist & 18 & 28.6 \\
\hline Very dangerous, need treatment in the hospital & 7 & 11.1 \\
\hline
\end{tabular}

* The total number can be more than 63 as a mother have more than one under-five child exposed to previous history of injuries.

** The total number can be more than 63 as injuries caused by more than one cause. 
Heba M. Nageh et. al.

Table 5 :Mothers description to their homes environment*

\begin{tabular}{|c|c|}
\hline Items & $\mathrm{n}=100$ \\
\hline \multicolumn{2}{|l|}{ Homes components } \\
\hline Chairs or tables are located near to windows or balconies & 58 \\
\hline Furniture located in the middle of the room & 41 \\
\hline $\begin{array}{l}\text { Furniture located in sides the room without sufficient space to } \\
\text { allow the freedom of individuals' movement }\end{array}$ & 39 \\
\hline No handrails for balconies & 29 \\
\hline Handrails is low & 31 \\
\hline No grates on windows & 54 \\
\hline Children toys are scattered in rooms after playing & 37 \\
\hline No barriers to the child bed & 57 \\
\hline Not have child bed & 15 \\
\hline Insufficient lighting at night & 69 \\
\hline No safety belt in the child chair or walker & 14 \\
\hline Not have child chair or walker & 47 \\
\hline \multicolumn{2}{|l|}{ Kitchen and bathroom } \\
\hline Leaving the kitchen floors wet & 60 \\
\hline Leaving the bathroom floors wet & 52 \\
\hline Leaving matches or lighters on tables & 64 \\
\hline Leaving the stove torches after use & 0 \\
\hline $\begin{array}{l}\text { Leaving cooking pots' panhandle out-bounded in front of the } \\
\text { stove }\end{array}$ & 20 \\
\hline Leaving hot pots accessible for children & 12 \\
\hline Leaving drawers opened in the reach of children & 11 \\
\hline Easiness of opening of the kitchen drawers & 42 \\
\hline Uncovered litter box & 16 \\
\hline Leaving the gas pipes opened continuously & 22 \\
\hline No smoking alarm & 96 \\
\hline Insufficient lighting & 3 \\
\hline \multicolumn{2}{|l|}{ Stairs } \\
\hline No handrails for stairs & 44 \\
\hline Wide stairs are not suitable for children & 44 \\
\hline Stairs are broken & 28 \\
\hline No gates or safety barriers on front of stairs & 91 \\
\hline Insufficient lighting at night & 2 \\
\hline \multicolumn{2}{|l|}{ Toxic substances and appliances } \\
\hline $\begin{array}{l}\text { Putting liquid detergents in drinking water bottles or in bottles of } \\
\text { carbonated water }\end{array}$ & 71 \\
\hline Store detergents in accessible places for children & 75 \\
\hline Store medicines in accessible places for children & 73 \\
\hline Leaving the iron operated after use in unsafe place & 2 \\
\hline
\end{tabular}

* The total number can be more than 100 as more than one answer was allowed 
MOTHERS' KNOWLEDGE AND SUBJECTIVE etc...

Table 6: Mothers' score level of knowledge regarding domestic injuries

\begin{tabular}{|c|c|c|c|c|}
\hline \multirow{2}{*}{ Items } & \multicolumn{3}{|c|}{$n=100$} & \multirow{2}{*}{ Mean (SD) } \\
\hline & Poor & Fair & Good & \\
\hline Meaning of home injuries ( 2 items) & 54 & 46 & 0 & $.460(.501)$ \\
\hline Risk groups to home injuries (6 items) & 68 & 32 & 0 & $2.180(1.038)$ \\
\hline Causes of home injuries ( 8 items) & 70 & 19 & 11 & $3.210(1.659)$ \\
\hline Types of home injuries (11 item) & 65 & 32 & 3 & $4.550(2.213)$ \\
\hline $\begin{array}{l}\text { Common consequences of home } \\
\text { injuries ( } 4 \text { items) }\end{array}$ & 100 & 0 & 0 & $.950(.219)$ \\
\hline $\begin{array}{l}\text { Ways of prevention of home injuries ( } 7 \\
\text { items) }\end{array}$ & 100 & 0 & 0 & $2.380(1.003)$ \\
\hline \multicolumn{5}{|l|}{ Poisoning } \\
\hline Poisoning types (4 items) & 83 & 17 & 0 & $.870(.676)$ \\
\hline Poisoning causes ( 7 items) & 88 & 12 & 0 & $2.260(1.169)$ \\
\hline Poisoning symptoms (11 item) & 90 & 10 & 0 & $3.280(2.156)$ \\
\hline Poisoning prevention (10 items) & 90 & 10 & 0 & $2.970(1.566)$ \\
\hline \multicolumn{5}{|l|}{ Burns } \\
\hline Burns types (3 items) & 78 & 22 & 0 & $1.140(.532)$ \\
\hline Burns causes ( 5 items) & 100 & 0 & 0 & $1.740(.525)$ \\
\hline $\begin{array}{l}\text { Burns prevention during bathing ( } 3 \\
\text { items) }\end{array}$ & 98 & 2 & 0 & $.940(.312)$ \\
\hline $\begin{array}{l}\text { Burns prevention from hot liquids } \\
\text { foods ( } 7 \text { items) }\end{array}$ & 100 & 0 & 0 & $2.480(.926)$ \\
\hline $\begin{array}{l}\text { Burns prevention from hot materials or } \\
\text { appliances ( } 5 \text { items) }\end{array}$ & 100 & 0 & 0 & $1.660(.655)$ \\
\hline \multicolumn{5}{|l|}{ Falls } \\
\hline Falls causes ( 8 items) & 96 & 4 & 0 & $2.530(1.058)$ \\
\hline Falls prevention (9 items) & 95 & 5 & 0 & $3.180(1.559)$ \\
\hline
\end{tabular}

Poor $=$ scores less than $50 \%$ of total scores

Fair $=$ scores $50 \%$ to less than $75 \%$ of total scores

Good $=$ scores $75 \%$ to $100 \%$ of total scores

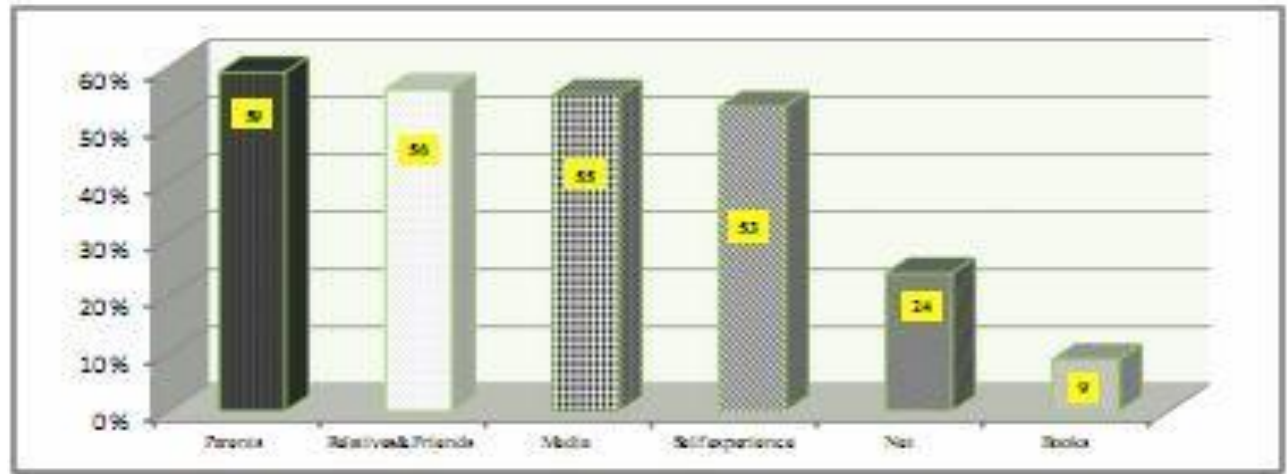

Figure 2 :Mothers' knowledge sources about domestic injuries $*(n=100)$

* The total number can be more than 100 as a mother can have more than one source of knowledge 
Heba M. Nageh et. al.

Table 7: Mothers' score level of subjective practice related to safety measures taken at home environment to prevent domestic injuries

\begin{tabular}{lccl}
\hline \multirow{2}{*}{ Items } & \multicolumn{2}{c}{$\mathbf{n = 1 0 0}$} & \multirow{2}{*}{ Mean (SD) } \\
\cline { 2 - 3 } & Improper & Proper & \\
\hline Poisoning (12 item) & 100 & 0 & $3.390(1.286)$ \\
Burns (3 items) & 100 & 0 & $2.010(.688)$ \\
Falls (14 item) & 100 & 0 & $5.480(1.141)$ \\
\hline
\end{tabular}

Improper $=$ scores less than $75 \%$ of total scores

Proper $=$ scores more than $75 \%$ of total scores

\section{References}

1. CDC (Centers for Disease Control and Prevention) National Center for Injury Prevention and Control (2014). WISQARS non-fatal injury data. Available at:

http://www.cdc.gov/injury/wisqars/no nfatal.html.

2. Bhalla K, Harrison JE, Shahraz S, Fingerhut LA, (2010). Availability and quality of cause-of-death data for estimating the global burden of injuries. Bull World Health Organization; 88(11):831e8.

3. WHO (World Health Organization) (2010). Injuries and violence, the facts. Geneva: Switzerland. Available at:

https://www.who.int/violence injury prevention/key facts/VIP key facts.p df?ua $=1$

4. Kamal NN, (2013). Home unintentional non-fatal injury among children under 5 years of age in a rural area, el Minia Governorate, Egypt. Journal of community health; 38(5): 873-9

5. WHO (World Health Organization) (2008). Causes of Death 2008. Available at:

http://www.who.int/gho/child_health/ mortality/mortality_under_five/en/.

6. United Nations Children's Fund (2014). Compromisso com a sobre- vivência infantil: uma promessa. Relatório de progresso 2014. Resumo executivo. Brasil: UNICEF; 2014.11. Available at: https://au.int/sites/default/files/docum ents/35488-doc

7. De Ramirez, S. S., Hyder, A. A., Herbert, H. K., \& Stevens, K. (2012). Unintentional injuries: Magnitude, prevention, and control. Annual Review of Public Health, 33, 175-191.

8. Bisha D, Trevltt JL, Zhang Y, Mc Kenzle LB, Leventhal T, Glelen AC, Guyer B (2008). Risk factors for unintentional injuries in children: Are grandparents Protective? Paediatrics 2008; 122: e980-7.

9. Hyginus, E.O., Okechukwu, U.J., Victor, I.M., Christian, O.C. and Anthony. U. (2015). Epidemiology of Admitted Cases of Childhood Injuries in Nnamdi Azikiwe University Teaching Hospital Nnewi, Nigeria. Annals of Tropical Medicine and Public Health, 8, 272-275.

10. NICE (National Institute for Health and Clinical Excellence) (2010). Public health guidance 29: Strategies to prevent unintentional injuries among under-15s. Available at www.evidence.nhs.uk 
11. Bombaci H, Ulku K, Adiyeke L, Kara S, Gorge M. (2008). Childhood injuries, their etiologies and preventive measures. Acta Orthop Traumatol Turc; 42: 166-73

12. Bashour H, Kharouf M. (2008). Community-based study of unintentional injuries among preschool children in Damascus. East Mediterr Health J 2008, 14:398-405.

13. Mahalakshmy, T.; Dongre, A.R.; Kalaiselvan, G. (2011). Epidemiology of childhood injuries in rural Puducherry, South India. Indian J. Pediatr. 2011, 78, 821-825.

14. Sengoelge, M.; Hasselberg, M.; Laflamme, L. (2011). Child home injury mortality in Europe: A 16country analysis. Eur. J. Public Health 2011, 21, 166-170.

15. Zia, N.; Khan, U.R.; Razzak, J.A.; Puvanachandra, P.; Hyder, A.A. (2012). Understanding unintentional childhood home injuries: Pilot surveillance data from Karachi, Pakistan. BMC Res.

16. Ramazani, A.B., \& Izad khah, M.H. (2011). Epidemiologic study and relationship factors of home injuries in clienteles to Birjand. Journal of Rostamineh, 2(3), 7179.

17. Khaliq, A., Amreen, Siddiqui, S. and Nasir, G.M. (2017). Assessment of Childhood Domestic Injuries among Joint and Nuclear Families of Karachi. Open Journal of Social Sciences, 5, 50-59.

18. Parmeswaran, G. G., Kalaivani, M., Gupta, S. K., Goswami, A. K., \& Nongkynrih, B. (2017). Unintentional childhood injuries in urban Delhi: A community-based study. Indian journal of community medicine: official publication of
Indian Association of Preventive \& Social Medicine, 42(1), 8.

19. Villaveces, A., Mutter, R., Owens, P.L. and Barrett, M.L. (2013). Causes of Injuries Treated in the Emergency Department, 2010. Agency for Healthcare Research and Quality, Rockville, 1-8.

20. Awqati NA, Ali MM, Al-Ward NJ, Majeed FA, Salman K, Al-Alak M, Al-Gasseer N. (2009). Causes and differentials of childhood mortality in Iraq. BMC

21. Mutto,M., Lett, R., Lawoko, S., Nansamba, C., \& Svanstrom, L., (2010). Intentional injuries among Ugandan youth: a trauma registry analysis. Injury Prevention Journal. 16:333e336. doi:10.1136/ip.2008.02049

22. Whelan A. (2015). The health visitor's role in reducing unintentional injury in the under-5s, Journal of Health Visiting

23. Kamel EG, Emam SA, Mohammed ES. (2014). Knowledge, attitude and practice among rural mothers about home-related injuries in a rural area in El-Minia Governorate, Egypt SJPH 2014; 2:653-659.

24. Yousefzadeh S, Hemmati H, Alizadeh A, Karimi A, Ahmadi M, Mohammadi H. (2008). Paediatric Unintentional Injuries in North of Iran. A short communication. Iran J Pediatr 2008; 18: 267-71.

25. Alazab RM. (2012). Determinants of Acute Poisoning among Children (160) months Old at a Poisoning Unit of a University Hospital, Egypt, are Employed Mothers a Risk Factor? Retrospective Cohort Study.

26. Mutairi, M., Harthy, N., Qahtani, A., Fahmi, S., Zidi, B., \& Ruqaya Essa Jaffer RE. (2016). Home Injury Prevention in Children: Attitude \& 
Awareness of the Caregivers at King Abdul-Aziz Medical City_Pediatric Emergency, Riyadh, KSA. Br J Med Med Res, 18(11), 1-10.

27. Nour MO., Alharbi WD., Alawneh SM., Ansari AZ., Luqmani AD., Alharbi AF., Sonari MA., Hassani HK. \& Malki AH. (2018). Knowledge, attitude and practices of mothers towards home accidents among children, makkah, ksa ejpmr, 2018,5(2), 139-147 Nour et al. European Journal of Pharmaceutical and Medical Research

28. Atak N, Karaoğlu L, Korkmaz Y, Usubutun S. (2010). A household survey: unintentional injury frequency and related factors among children under five years in Malatya. Turk $\mathbf{J}$ Pediatr 2010: 52; 285-293.

29. El Seifi OS, Mortada EM, Abdo NM (2018) Effect of communitybased intervention on knowledge, attitude, and self-efficacy toward home injuries among Egyptian rural mothers having preschool children. PLoS ONE 13(6): e0198964.

30. Mohammed AR, Mohammed NS, Byoumi MH. (2013). Supportive strategies regarding accidents prevention for mothers of children under five years old. JBAH 2013; $3: 1-11$.

31. Eldosoky RSH. (2012). Home related injuries among children: knowledge, attitudes and practice about first aid among rural mothers. East Mediterr Health J. 2012.

32. Rezapur-Shahkolai, F., Afshari, M., Moghimbeigi, A., \& Hazavehei, S. M. M. (2017). Home-related injuries among under-five-year children and mothers' care regarding injury prevention in rural areas. International journal of injury control and safety promotion, 24(3), 354-362.
33. Ümmühan Aktürk* \& Behice Erci. (2016). Determination of Knowledge, Attitudes and Behaviors Regarding Factors Causing Home Accidents and Prevention in Mothers with a Child Aged 0-5 Years, Journal of Education and Practice. Vol.7, No.18, 2016, Public Health Nursing, Inonu University, Malatya, Turkey/44280.

34. Mutto M., Lawoko S., Nansamba C., Ovuga E., Svanstrom L. (2011). Unintentional childhood injury patterns, odds, and outcomes in Kampala City: an analysis of surveillance data from the National Pediatric Emergency Unit.

35. Zaidi SHN, Khan Z, Khalique N. (2013). Injury pattern in children: a population-based study. Indian journal of community health, Vol. 25, No. 1, Jan-Mar 2013.

36. Hyder, A., Sugerman, D., Puvanachandra, P., et al. (2009). Global childhood unintentional injury surveillance in four cities in developing countries: A pilot study. Bulletin of the World Health Organization, 87, 345-352.

37. Khoon WC. (2012) Home safety and prevention of home accidents in young children. Bulletin, p: 24.

38. İnce $\mathbf{T}$, Yalçın $\mathbf{S}$, Yurdakök $\mathbf{K}$. (2017). Parents' Attitudes and Adherence to Unintentional Injury Prevention Measures in Ankara, Turkey. Balkan Med J 2017;34:33542

39. Vladutiu CJ, Nansel TR, Weaver NL, Jacobsen HA, Kreuter MW. (2006). Differential strength of association of child injury prevention attitudes and beliefs on practices: a case for audience segmentation. Inj Prev 2006;12:35-40.

40. Vincenten JA, Sector MJ, Rogmans W, Bouter L. (2005). Parents' 
perceptions, attitudes and behaviours towards child safety: a study in 14 European countries. Int J Inj Contr Saf Promot 2005;12:183-9.

41. Sackitey GL (2018). Knowledge, Attitude and Perception on Prevention of Home Accidents among Mothers who Came to the Pediatrics Department of the Korle-Bu Teaching Hospital. J Health Educ Res Dev 6: 242.

42. El- Sabely AA, Yassin AI, Zaher SA. (2014). Mother's education and her knowledge about home accident prevention among preschool children in rural area in Sharkia governorate. Journal of Nursing and Health Science JNHS 2014; 3:32-40.

43. Lafta RK, Al- Shatari SA, Abass S. (2013). Mothers' knowledge of domestic accident prevention involving children in Baghdad City. QMJ 2013; 2:50-56.

44. Wang X, Chen N, Shi Z, Zhao Z. (2012). An investigation on knowledge-attitude-practice about injury and the related factors among school children's parents in Jinan,
China. Int J Inj Contr Saf Promot 2012; 19:267-271.

45. Hatamabadi HR, Mahfoozpour S, Alimohammadi H, Younesian S. (2014). Evaluation of factors influencing knowledge and attitudes of mothers with preschool children regarding their adoption of preventive measures for home injuries referred to academic emergency centres, Tehran, Iran. Int J Inj Contr Saf Promot 2014; 21:252-259.

46. Debnath, M., Reang, T., \& Tripura. A. (2014). A study to assess the knowledge of rural mothers regarding common domestic childhood injuries and home-safety measures adopted by them in west district of Tripura, India. J Evol Med Dental Sci, 3(20), 5522-8.

47. Tsoumakas K., Dousis E., Mavridi F., Gremou A. \& Matziou V. (2009) Parent's adherence to children's home-accident preventive measures. International Nursing Review 56, 369-374 